\title{
BMJ Open A cost of illness study of hypoglycaemic events in insulin-treated diabetes in the Netherlands
}

\author{
Saskia de Groot, ${ }^{1}$ Catherine F Enters-Weijnen, ${ }^{2,3}$ \\ Petronella H Geelhoed-Duijvestijn, ${ }^{4}$ Tim A Kanters ${ }^{1}$
}

To cite: de Groot S, EntersWeijnen CF, GeelhoedDuijvestijn PH, et al. A cost of illness study of hypoglycaemic events in insulin-treated diabetes in the Netherlands. BMJ Open 2018;8:e019864. doi:10.1136/ bmjopen-2017-019864

- Prepublication history and additional material for this paper are available online. To view these files, please visit the journal online (http://dx.doi. org/10.1136/bmjopen-2017019864).

Received 2 0ctober 2017 Revised 29 January 2018 Accepted 5 February 2018

Check for updates

${ }^{1}$ Institute for Medical Technology Assessment, Erasmus University Rotterdam, Rotterdam, The Netherlands

${ }^{2}$ Julius Clinical, Zeist, The Netherlands

${ }^{3}$ Julius Center for Health

Sciences and Primary

Care, University Medical

Center Utrecht, Utrecht, The

Netherlands

${ }^{4}$ Department of Internal

Medicine, Haaglanden Medical

Center, The Hague, The

Netherlands

Correspondence to

Dr Saskia de Groot;

degroot@imta.eur.nl

\section{ABSTRACT}

Objectives Patients with diabetes mellitus are at a risk for hypoglycaemia. Besides the burden of hypoglycaemia for patients, hypoglycaemia poses an economic burden to society. The aim of this study was to calculate the per patient societal costs of hypoglycaemia among patients with type1 diabetes (T1DM) and type 2 diabetes (T2DM) on insulin therapy in the Netherlands.

Methods To calculate the costs of hypoglycaemia, data from the Global Hypoglycaemia Assessment Tool (HAT) study were used. Dutch patients were selected from the HAT study database and data regarding healthcare resource use, informal care use and productivity losses were combined with Dutch unit costs to calculate the per patient 4-week costs of patients experiencing hypoglycaemia. Besides these 4-week costs, costs per hypoglycaemic event were calculated by dividing the study population total 4 -week costs by the total number of events in this period.

Results Mean 4-week total costs of hypoglycaemia amounted to $€ 163$ (SD, €870) in T1DM and €134 (SD, $€ 364)$ in T2DM. While productivity costs were the most important cost driver of hypoglycaemia in patients with T1DM (accounting for $72 \%$ of the total costs), costs of hypoglycaemia in patients with T2DM were almost entirely driven by costs within the healthcare sector (accounting for $98 \%$ of the total costs). Mean costs of a severe hypoglycaemic event were $€ 828$ and $€ 508$ in T1DM and T2DM, respectively, whereas mean costs of a non-severe event were almost zero.

Conclusions This study showed that the economic burden of severe hypoglycaemia is substantial. The prevention of hypoglycaemia could therefore not only reduce the burden for patients, but also the economic burden to society.

\section{INTRODUCTION}

Worldwide 382 million individuals suffer from diabetes mellitus. ${ }^{1}$ The estimated prevalence of diabetes in the Netherlands was 1.1 million in 2015. ${ }^{2}$ Between 1991 and 2014, the prevalence of diabetes in men has more than doubled, and the prevalence in women has increased by $50 \%{ }^{2}$ The prevalence is expected to increase further because of the ageing population and due to an increase in

\section{Strengths and limitations of this study}

In the Netherlands, 150 general practitioners and 18 hospitals (including 2 academic hospitals) participated in the study.

- Patient-level data were collected using a SelfAssessment Questionnaire (SAQ) on the impact of hypoglycaemia on healthcare and informal care utilisation and productivity.

- For some questions from the $S A Q$, it was unclear if the resources were used as a consequence of a severe or non-severe event; assumptions were made to calculate the costs of patients with severe hypoglycaemia and patients with non-severe hypoglycaemia.

- Results from the SAQ (including the results regarding the number of events) might suffer from recall bias.

the number of people being overweight or having other risk factors for diabetes. ${ }^{3}$

Patients with diabetes mellitus are at risk for hypoglycaemia, which is caused by medications used to treat diabetes mellitus, such as insulin or oral hypoglycaemic medications, combined with reduced carbohydrate intake or increased activity. Khunti et al have shown that the rate of any hypoglycaemic event was 73.3 events per patient-year for type 1 diabetes (T1DM) and 19.3 events per patient-year for type 2 diabetes (T2DM) treated with insulin. ${ }^{4}$ Hypoglycaemia is mostly associated with mild symptoms, such as sweating, dizziness or headache, but hypoglycaemia can also lead to unconsciousness or coma. Moreover, hypoglycaemia is associated with more future events. ${ }^{5}$

Besides the burden for patients, hypoglycaemia poses an economic burden to society. Hypoglycaemic events can lead to healthcare use, such as ambulance transport, hospital admissions and clinical appointments. Healthcare costs of hypoglycaemia have been estimated in different countries, ${ }^{6-10}$ but the costs of hypoglycaemia in the Netherlands are unknown. In addition to the healthcare costs, 
hypoglycaemia is expected to lead to societal costs due to lost productivity and time costs for informal caregivers, but these estimates are also lacking. The aim of this study was therefore to calculate the per patient societal costs of hypoglycaemia among insulin-treated patients with T1DM and T2DM in the Netherlands.

\section{METHODS}

To calculate the costs of hypoglycaemia, data from the Global Hypoglycaemia Assessment Tool (HAT) study were used. ${ }^{4}$ The primary objective of the HAT study was to determine the percentage of patients experiencing at least one hypoglycaemic event during the 4-week follow-up period among insulin-treated patients with T1DM and T2DM. The HAT study was a non-interventional, multicentre, 6-month retrospective and 4-week prospective study. Patients were invited to participate by their healthcare provider during routine scheduled clinical appointments if they fulfilled the following inclusion criteria: (1) having T1DM or T2DM and treated with insulin for $>12$ months; (2) being $\geq 18$ years at the time of the survey and (3) giving informed consent to participate in the study. Non-ambulatory patients were excluded. The HAT study was conducted in 24 countries. To calculate the costs of hypoglycaemia in the Netherlands, Dutch patients were selected from the HAT study database. In the Netherlands, 150 general practitioners and 18 hospitals (including 2 academic hospitals) participated in the study. Patients originated from urban and rural areas from all over the Netherlands. Patients were invited to participate during routine clinical visits and were not actively approached to participate otherwise.

In the HAT study, a Self-Assessment Questionnaire (SAQ) was used, consisting of two parts. In the first part, data about baseline demographics and treatment were collected.
Additionally, questions regarding knowledge, awareness and perceptions of hypoglycaemia were asked. Lastly, information about the history of severe hypoglycaemia over the last 6 months and non-severe hypoglycaemia over the last 4 weeks was collected. A severe event was defined as hypoglycaemia which requires assistance from another person to administer carbohydrate and/or glucagon. ${ }^{11}$ Hypoglycaemia resulting in hospital admission and hypoglycaemia requiring assistance from medical personnel but not requiring hospital admission were also regarded as severe in this study. Non-severe hypoglycaemia was defined as hypoglycaemia managed by the patient alone. Part 1 of the questionnaire was provided to patients during a routine clinical appointment with a healthcare professional, and patients were asked to complete and return the questionnaire during the visit. In the next 4 weeks, patients were asked to fill in a diary to capture hypoglycaemic events. After 4 weeks, patients were asked to complete part 2 of the questionnaire, which assessed the history of both severe and non-severe hypoglycaemia in the previous 4 weeks. Both part 1 and part 2 of the SAQ also included questions regarding the impact of hypoglycaemia on healthcare and informal care utilisation and productivity. The patient questionnaire is provided in the online supplementary appendix 1 . Figure 1 shows the design of the study.

Costs of hypoglycaemic events within the healthcare sector were calculated by combining healthcare utilisation as derived from the SAQ with Dutch unit costs. Unit costs were derived from the Dutch costing manual, ${ }^{12}$ except for the costs of extra blood glucose tests (these were derived from a report by the Dutch National Healthcare Institute about the reimbursement and quality of blood glucose test material ${ }^{13}$ ) and the costs of glucose administered by medical professionals during a hypoglycaemic event (these were derived from medicijnkosten. $\mathrm{nl}^{14}$ ). Besides

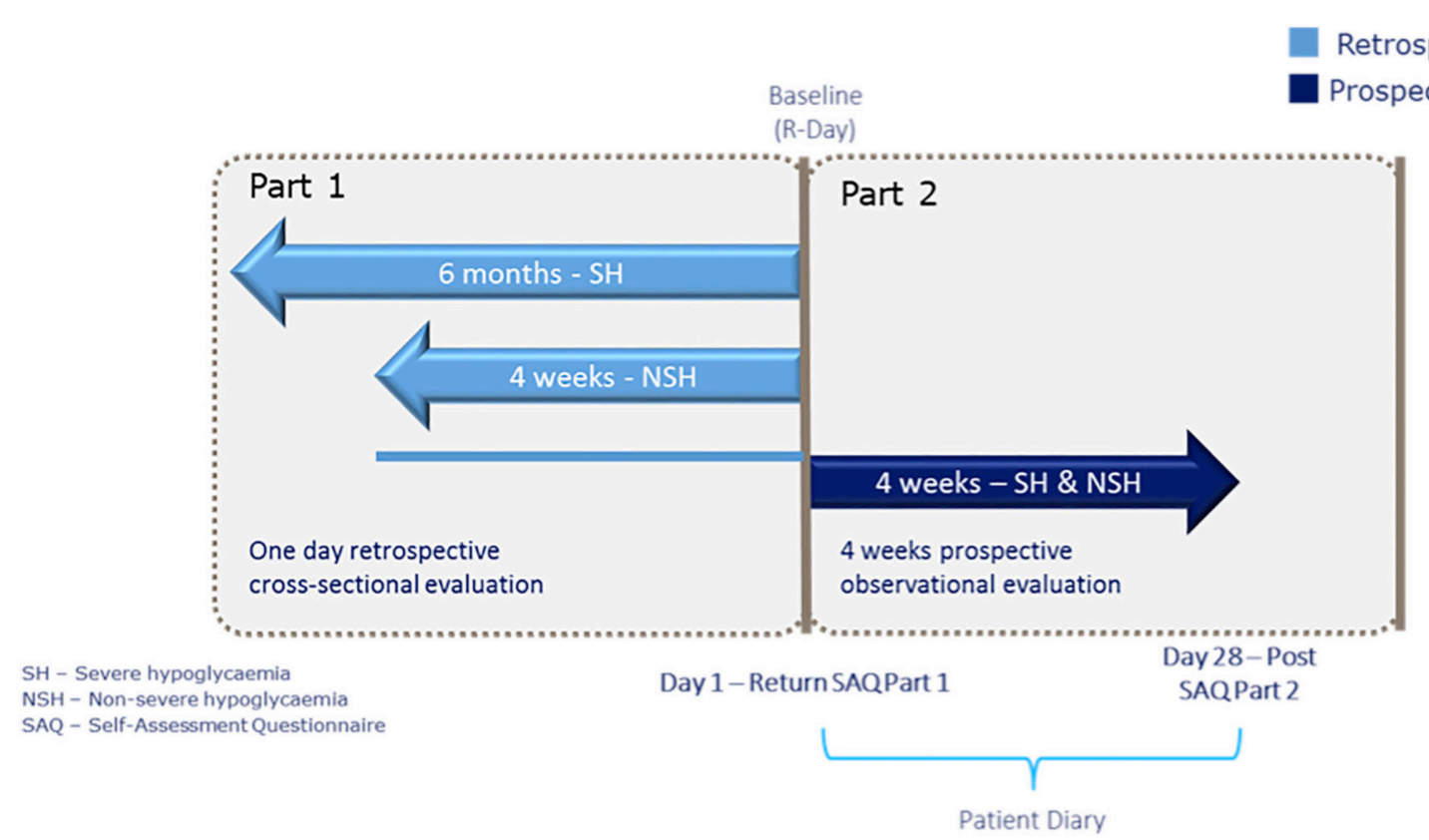

Figure 1 Design of the HAT study. ${ }^{4}$ 
the costs within the healthcare sector, informal care costs were calculated by combining informal care use with time costs of informal caregivers which were also derived from the Dutch costing manual. ${ }^{12}$ In order to calculate the costs of hypoglycaemic events within the healthcare sector and the costs of informal care, the following assumptions were made: (1) patients admitted to a hospital as a result of a hypoglycaemic event arrived at the hospital with an ambulance; (2) $75 \%$ of patients requiring assistance from medical personnel but not requiring hospital admission was treated at home by ambulance personnel and $25 \%$ was treated by a general practitioner (only applicable to patients with severe hypoglycaemia); (3) patients requiring assistance from medical personnel received an intravenous infusion (or injection) with glucose; (4) patients requiring assistance from another person (non-medical) to administer carbohydrate and/or glucagon were given assistance by an informal caregiver and this assistance was assumed to take 1 hour for patients with T1DM and 3 hours for patients with T2DM; (5) patients with T1DM who had an additional clinical appointment with a doctor or nurse visited the hospital, whereas patients with T2DM who had an additional clinical appointment with a doctor or nurse visited the general practitioner.

Productivity costs were calculated by combining productivity losses as derived from the SAQ with hourly productivity costs from the Dutch costing manual. ${ }^{12}$ Hourly productivity costs were $€ 32$ for female patients and $€ 38$ for male patients. To calculate the productivity costs of hypoglycaemic events, two additional assumptions were made: (6) a working day was assumed to be 8 hours (for patients with a full-time and part-time job); (7) patients arriving at work late or leaving work early were absent from work for half a day. Productivity costs were zero for students and patients who were unemployed or patients who were retired from work.

If a question regarding resource use remained unanswered, it was assumed that the patient did not use this specific type of resource use. Missing data regarding the frequency of healthcare use (if a patient indicated that he had used a specific type of resource use) were handled by imputing the mean of the available data. In this way, all patients were included in the calculation of total costs including patients with missing values on some, but not all variables.

Base case analyses present the per patient 4-week costs as derived from part 2 of the SAQ (ie, the 4 week prospective study). Results were reported separately for patients with T1DM and T2DM. Within these two categories, a further distinction was made between patients with hypoglycaemia including at least one severe event and for patients with non-severe events only. Results of part 1 of the SAQ (ie, 6-month retrospective study) were provided in the online supplementary materials.

The impact of assumptions 2, 4 and 7 on the total 4-week costs of patients experiencing hypoglycaemia were tested in univariate sensitivity analyses. First, the proportion of patients treated at home by a general practitioner or ambulance personnel was varied, that is, $50 \%$ or $0 \%$ treated at home by a general practitioner (instead of $25 \%)$ and $50 \%$ or $100 \%$ treated by ambulance personnel (instead of $75 \%$ ). Second, the duration of assistance by an informal caregiver was doubled, that is, 2 hours for T1DM (instead of 1 hour) and 6 hours for T2DM (instead of 3 hours). Third, the hours that patients were absent from work if they indicated that they arrived at work late or left work early were halved, that is, 2 hours instead of 4 hours. In addition to these assumptions, the impact of higher unit costs $(+20 \%)$ of an ambulance was studied.

Besides the per patient total 4-week costs of patients experiencing hypoglycaemia, costs were calculated per hypoglycaemic event. To calculate these costs, the study population total 4-week costs were divided by the total number of events in this period. The total number of events was derived from the SAQ and patient diary. Since number of events according to the SAQ and patient diary differed, two point estimates of the costs of an event were provided.

Additionally, the total costs of hypoglycaemia among insulin-treated patients with T1DM and T2DM in the Netherlands were estimated using information on the total number of insulin-users in the Netherlands. According to the Dutch Foundation for Pharmaceutical Statistics (SFK), there were 310000 insulin-users in the Netherlands in 2014. ${ }^{15}$ Assuming that all patients with T1DM use insulin and that the estimated prevalence of diabetes in the Netherlands was 1.1 million in 2015, and $9 \%$ (ie, 99000 patients) had T1DM, ${ }^{2}$ the estimated number of insulin-users is 99000 in T1DM and 211000 in T2DM (ie, 310000 minus 99 000). These numbers were then multiplied by the proportion of patients experiencing hypoglycaemia, and the per patient 4-week costs (extrapolated to yearly costs) of these latter patients.

All costs were reported in Euro 2016. Wherever necessary, costs were adjusted to 2016 values using the consumer price index derived from Statistics Netherlands. ${ }^{16}$

\section{RESULTS}

\section{Patient and disease characteristics}

Six hundred and thirty-three patients returned part 2 of the SAQ that is, 142 patients with T1DM and 491 patients with T2DM. Table 1 shows the patient and disease characteristics. The median age was 46 years for patients with T1DM and 68 years for patients with T2DM. The duration of diabetes was 18.6 years $(\mathrm{SD}, 12.1)$ and 14.2 years (SD, 8.0) for patients with T1DM and T2DM, respectively. Patients with T2DM used insulin, on average, for 7.7 years (SD, 6.1). Levels of glycaemic control (ie, HbA1c) were similar across patients with T1DM and T2DM $(59.3 \mathrm{mmol} /$ mol $(7.3 \%)$ vs $57.7 \mathrm{mmol} / \mathrm{mol}(7.6 \%))$.

In the 4 weeks after baseline, $92 \%$ of the patients with T1DM and $43 \%$ of the patients with T2DM experienced one or more hypoglycaemic events. Of these patients, $10 \%$ and $15 \%$ experienced at least one severe event, and almost all these patients (ie, 98\% and 96\%) experienced 
Table 1 Patient and disease characteristics

\begin{tabular}{|c|c|c|c|}
\hline & All patients $(n=633)$ & T1DM (n=142) & T2DM $(n=491)$ \\
\hline Age, median (range) & $65(18-92)$ & $46(18-82)$ & $68(30-92)$ \\
\hline \multicolumn{4}{|l|}{ Sex, n (\%) } \\
\hline Female & $319(50)$ & $79(56)$ & $240(49)$ \\
\hline Male & $314(50)$ & $63(44)$ & $251(51)$ \\
\hline Years with diabetes, mean (SD) & $15.2(9.3)$ & $18.6(12.1)$ & $14.2(8.0)$ \\
\hline Years on insulin, mean (SD) & $10.0(9.0)$ & $17.9(12.2)$ & $7.7(6.1)$ \\
\hline $\mathrm{HbA} 1 \mathrm{c}, \mathrm{mmol} / \mathrm{mol}$, mean (SD) & $58.0(11.8)$ & $59.3(12.6)$ & $57.7(11.5)$ \\
\hline HbA1c, \%, mean (SD) & $7.5(1.3)$ & $7.3(1.2)$ & $7.6(1.4)$ \\
\hline \multicolumn{4}{|l|}{ Checks blood glucose levels, $n(\%)$} \\
\hline Yes & $618(98)$ & $141(99)$ & $477(97)$ \\
\hline No & $12(2)$ & $1(1)$ & $11(2)$ \\
\hline Missing & $3(0)$ & $0(0)$ & $3(1)$ \\
\hline \multicolumn{4}{|l|}{ Method of diabetes treatment, $\mathrm{n}(\%)$} \\
\hline Insulin - short-acting & $323(51)$ & $103(73)$ & $220(45)$ \\
\hline Insulin - long-acting & $444(70)$ & $79(56)$ & $365(74)$ \\
\hline Insulin - mixed & $114(18)$ & $6(4)$ & $108(22)$ \\
\hline Insulin pump & $60(9)$ & $52(37)$ & $8(2)$ \\
\hline Oral glucose lowering drugs & $152(24)$ & $6(4)$ & $146(30)$ \\
\hline \multirow[t]{2}{*}{ Injectable glucose-lowering treatments excluding insulin } & $8(1)$ & $0(0)$ & $8(2)$ \\
\hline & All patients $(n=612)^{*}$ & T1DM $(n=141)$ & T2DM $(n=471)$ \\
\hline Number of patients with one or more hypoglycaemic events, $n(\%)$ & $332(54)$ & $130(92)$ & $202(43)$ \\
\hline Severe hypoglycaemia & $43(13)$ & $13(10)$ & $30(15)$ \\
\hline Non-severe hypoglycaemia & $322(97)$ & $128(98)$ & $194(96)$ \\
\hline Nocturnal hypoglycaemia & $130(39)$ & $66(51)$ & $64(32)$ \\
\hline
\end{tabular}

${ }^{*}$ Data from 21 patients were missing.

T1DM, type 1 diabetes; T2DM, type 2 diabetes.

at least one non-severe event. Fifty-one per cent and $32 \%$ of the patients with T1DM and T2DM who experienced hypoglycaemia, respectively, experienced (a) nocturnal hypoglycaemic event(s).

\section{Healthcare utilisation and informal care utilisation}

Table 2 shows the healthcare utilisation and informal care utilisation of those patients who experienced hypoglycaemia in the 4 weeks after baseline (patients without hypoglycaemia were excluded from the analyses). Only 43 patients (13\%) of the population had at least one event requiring (1) hospital admission (T1DM, 2\%; T2DM, $10 \%)$; (2) assistance from medical personnel but not requiring hospital admission (T1DM, 1\%; T2DM, 2\%); and/or (3) assistance from another person to administer carbohydrate and/or glucagon (T1DM, 9\%; T2DM, 6\%). Most patients (T1DM, 98\%; T2DM, 96\%) also had one or more events that they could manage themselves.

Actions undertaken by patients as a result of hypoglycaemic events are also presented in table 2. Fifteen per cent (T1DM, 21\%; T2DM 11\%) of the population addressed a hypoglycaemic event at the next scheduled clinic visit, 2\% (T1DM, 2\%; T2DM 1\%) attended an additional clinical appointment with a doctor or nurse, 8\% (T1DM, 7\%; T2DM 8\%) made additional telephone contacts with a doctor or nurse, $1 \%$ (T1DM, $1 \%$; T2DM $1 \%$ ) consulted another healthcare professional and $68 \%$ (T1DM, 70\%; T2DM 67\%) did not consult a doctor, nurse or healthcare professional if they experienced a hypoglycaemic event (note that this is the average of patients with hypoglycaemia including at least one severe event or non-severe events only).

Also, 26\% (T1DM, 27\%; T2DM 25\%) of the population increased the quantity of carbohydrates or number of snacks in diet, 7\% (T1DM, 8\%; T2DM 6\%) reduced the amount of sport or physical exercise, 29\% (T1DM, 39\%; T2DM 22\%) decreased the insulin dose, 15\% (T1DM, 16\%; T2DM 14\%) skipped the insulin dose, 53\% (T1DM, $58 \%$; T2DM 50\%) increased the number of blood glucose checks per day and $11 \%$ (T1DM, 16\%; T2DM 8\%) made any other change to diabetes treatment.

Per patient 4-week healthcare utilisation and informal care costs

Table 3 presents the 4-week healthcare utilisation costs and informal care costs of patients who experienced 
Table 2 Healthcare utilisation, informal care utilisation and additional actions of patients experiencing hypoglycaemia in 4 weeks after baseline

\begin{tabular}{|c|c|c|c|c|c|c|}
\hline $\begin{array}{l}\text { All } \\
(n=332)\end{array}$ & T1DM ( & $=130)$ & & T2DM ( & =202) & \\
\hline $\begin{array}{l}\text { All } \\
(n=332)\end{array}$ & $\begin{array}{l}\text { All } \\
(n=130)\end{array}$ & $\begin{array}{l}\text { Patients } \\
\text { with SH } \\
(n=13)\end{array}$ & $\begin{array}{l}\text { Patients } \\
\text { with NSH } \\
\text { (n=117) }\end{array}$ & $\begin{array}{l}\text { All } \\
(n=202)\end{array}$ & $\begin{array}{l}\text { Patients } \\
\text { with SH } \\
(n=30)\end{array}$ & $\begin{array}{l}\text { Patients } \\
\text { with NSH } \\
(n=172)^{*}\end{array}$ \\
\hline
\end{tabular}

\section{Patients indicated the following hypoglycaemic events (in the last 4 weeks) $\dagger$}

\begin{tabular}{|c|c|c|c|c|c|c|c|}
\hline Event resulting in hospital admission, $\mathrm{n}(\%)$ & $23(7)$ & $3(2)$ & $3(23)$ & $0(0)$ & $20(10)$ & $20(67)$ & $0(0)$ \\
\hline Times admitted, mean (SD) & $1.0(0.0)$ & $1.0(0.0)$ & $1.0(0.0)$ & - & $1.0(0.0)$ & $1.0(0.0)$ & - \\
\hline Admission length (days), mean (SD) & $1.1(0.4)$ & $1.7(1.2)$ & $1.7(1.2)$ & - & $1.0(0.0)$ & $1(0.0)$ & - \\
\hline $\begin{array}{l}\text { Event requiring assistance from medical } \\
\text { personnel but not requiring hospital admission, } \\
\mathrm{n}(\%)\end{array}$ & $6(2)$ & $1(1)$ & $1(8)$ & $0(0)$ & $5(2)$ & $5(17)$ & $0(0)$ \\
\hline Number of episodes, mean (SD) & $1.0(0.0)$ & $1.0(0.0)$ & $1.0(0.0)$ & - & $1.0(0.0)$ & $1.0(0.0)$ & - \\
\hline $\begin{array}{l}\text { Event requiring assistance from another person } \\
\text { to administer carbohydrate and/or glucagon } \\
\text { (informal care), } \mathrm{n}(\%)\end{array}$ & $24(7)$ & $12(9)$ & $12(92)$ & $0(0)$ & $12(6)$ & $12(40)$ & $0(0)$ \\
\hline Number of episodes, mean (SD) & $1.8(1.3)$ & $1.5(0.8)$ & $1.5(0.8)$ & - & $2.2(1.6)$ & $2.2(1.6)$ & - \\
\hline Event managed by the patient, $\mathrm{n}(\%)$ & $322(97)$ & $128(98)$ & $12(92)$ & $116(99)$ & $194(96)$ & $23(77)$ & $171(99)$ \\
\hline Number of episodes, mean (SD) & $5.1(5.2)$ & $8.6(6.3)$ & $10.5(8.1)$ & $8.5(6.0)$ & $2.7(2.4)$ & $2.0(1.6)$ & $2.8(2.5)$ \\
\hline Event occurred at night, $\mathrm{n}(\%)$ & $130(39)$ & $66(51)$ & $9(69)$ & $57(49)$ & $64(32)$ & $12(40)$ & $52(30)$ \\
\hline Number of episodes, mean (SD) & $2.1(1.8)$ & $2.5(2.2)$ & $3.3(3.1)$ & $2.4(2.1)$ & $1.6(1.0)$ & $1.7(1.2)$ & $1.6(0.9)$ \\
\hline
\end{tabular}

\section{Patients indicated the following actions (if they experienced a hypoglycaemic event in the last 4 weeks)}

Addressed the hypoglycaemic event at next $\quad 50(15) \quad 27(21) \quad 6(46) \quad 21(18) \quad 23(11) \quad 6(20) \quad 17(10)$ scheduled clinic visit, $\mathrm{n}(\%)$

Attended additional clinical appointments with $5(2) \quad 2(2) \quad 1(8) \quad 1(1) \quad 3(1) \quad 1(3) \quad 2(1)$
doctor/nurse, $n(\%)$

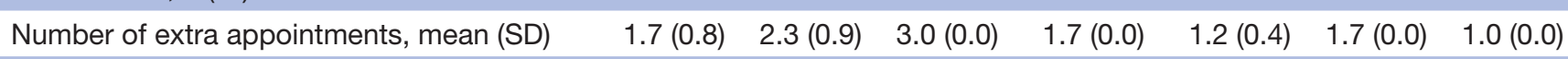

$\begin{array}{llllllll}\text { Rescheduled clinic appointment for an earlier } & 1(0) & 1(1) & 1(8) & 0(0) & 0(0) & 0(0) & 0(0)\end{array}$ time, $\mathrm{n}(\%)$

Made additional telephone contacts with $\quad 26(8) \quad 9(7) \quad 5(38) \quad 4(3) \quad 17(8) \quad 5(17) \quad 12(7)$

doctor/nurse, $\mathrm{n}(\%)$

$\begin{array}{llllllll}\text { Number of telephone contacts, mean (SD) } & 2.0(1.2) & 2.2(1.3) & 2.6(1.5) & 1.8(1.0) & 1.9(1.1) & 1.6(0.5) & 2.0(1.3)\end{array}$

(\%)

\begin{tabular}{|c|c|c|c|c|c|c|c|}
\hline $\begin{array}{l}\text { Did not consult a doctor/nurse/healthcare } \\
\text { professional, } n(\%)\end{array}$ & $227(68)$ & $91(70)$ & $5(38)$ & $86(74)$ & $136(67)$ & $11(37)$ & $125(73)$ \\
\hline $\begin{array}{l}\text { Increased the quantity of carbohydrates or } \\
\text { number of snacks in diet, } n(\%)\end{array}$ & $86(26)$ & $35(27)$ & $3(23)$ & $32(27)$ & $51(25)$ & $6(20)$ & $45(26)$ \\
\hline $\begin{array}{l}\text { Reduced the amount of sport or physical } \\
\text { exercise, } n(\%)\end{array}$ & $24(7)$ & $11(8)$ & $3(23)$ & $8(7)$ & $13(6)$ & $1(3)$ & $12(7)$ \\
\hline Decreased insulin dose, $\mathrm{n}(\%)$ & $96(29)$ & $51(39)$ & $7(54)$ & $44(38)$ & $45(22)$ & $7(23)$ & $38(22)$ \\
\hline Skipped insulin dose, $\mathrm{n}(\%)$ & $49(15)$ & $21(16)$ & $2(15)$ & $19(16)$ & $28(14)$ & $7(23)$ & $21(12)$ \\
\hline $\begin{array}{l}\text { Increased the number of blood glucose checks } \\
\text { per day, } \mathrm{n}(\%)\end{array}$ & $176(53)$ & $76(58)$ & $8(62)$ & $68(58)$ & $100(50)$ & $17(57)$ & $83(48)$ \\
\hline Number of extra checks, mean (SD) & $2.0(0.7)$ & $1.9(0.8)$ & $2.1(0.8)$ & $1.9(0.8)$ & $2.0(0.7)$ & $2.2(0.8)$ & $2.0(0.7)$ \\
\hline Number of days, mean (SD) & $4.3(5.1)$ & $5.5(4.1)$ & $5.5(3.9)$ & $5.5(4.2)$ & $3.4(5.5)$ & $5.9(8.9)$ & $2.9(4.5)$ \\
\hline $\begin{array}{l}\text { Made any other changes to diabetes treatment, } \\
\mathrm{n}(\%)\end{array}$ & $38(11)$ & $21(16)$ & $3(23)$ & $18(15)$ & $17(8)$ & $3(10)$ & $14(8)$ \\
\hline
\end{tabular}

*Note that these categories include patients with (a) non-severe event(s) only (and two patients (1T1DM patient and 1T2DM patient) with a nocturnal event only).

†Note that the percentages do not count to $100 \%$, because patients can have multiple hypoglycaemic events.

$\mathrm{NSH}$, non-severe hypoglycaemia; SH, severe hypoglycaemia; T1DM, type 1 diabetes; T2DM, type 2 diabetes. 
Table 3 Per patient healthcare utilisation costs and informal care costs of patients experiencing hypoglycaemia in 4 weeks after baseline

\begin{tabular}{|c|c|c|c|c|c|c|c|c|}
\hline & \multirow[b]{2}{*}{$\begin{array}{l}\text { Unit costs } \\
\text { (€) } 2016\end{array}$} & \multirow{2}{*}{$\begin{array}{l}\text { All }(n=332) \\
\text { All }(n=332)\end{array}$} & \multicolumn{3}{|c|}{ T1DM $(n=130)$} & \multicolumn{3}{|c|}{ T2DM $(n=202)$} \\
\hline & & & All $(n=130)$ & $\begin{array}{l}\text { Patients } \\
\text { with SH } \\
\text { ( } n=13)\end{array}$ & $\begin{array}{l}\text { Patients } \\
\text { with NSH } \\
\text { ( } \mathrm{n}=117)\end{array}$ & All $(n=202)$ & $\begin{array}{l}\text { Patients } \\
\text { with SH } \\
(n=30)\end{array}$ & $\begin{array}{l}\text { Patients with } \\
\text { NSH ( } n=172)\end{array}$ \\
\hline $\begin{array}{l}\text { Event resulting in hospital admission, } \\
\text { mean costs (SD) }\end{array}$ & $€ 480.29^{*}$ & $€ 79(€ 296)$ & $€ 33(€ 226)$ & $€ 329$ (€665) & $€ 0(€ 0)$ & $€ 109(€ 331)$ & $€ 737(€ 530)$ & $€ 0(€ 0)$ \\
\hline $\begin{array}{l}\text { Event requiring assistance from medical } \\
\text { personnel but not requiring hospital } \\
\text { admission, mean costs (SD) }\end{array}$ & $476.51 \dagger$ & $€ 9(€ 64)$ & $€ 4(€ 42)$ & $€ 37(€ 134)$ & $€ 0(€ 0)$ & $€ 12(€ 75)$ & $€ 81(€ 183)$ & $€ 0(€ 0)$ \\
\hline $\begin{array}{l}\text { Event requiring assistance from another } \\
\text { person to administer carbohydrate and/or } \\
\text { glucagon (informal care), mean costs (SD) }\end{array}$ & $€ 14.13$ & $€ 4(€ 21)$ & $€ 2(€ 7)$ & $€ 20(€ 12)$ & $€ 0(€ 0)$ & $€ 5(€ 27)$ & $€ 37$ (€62) & $€ 0(€ 0)$ \\
\hline \multicolumn{9}{|c|}{ Patients indicated the following actions (if they experienced a hypoglycaemic event in the last 4 weeks) } \\
\hline $\begin{array}{l}\text { Attended additional clinical appointments } \\
\text { with doctor/nurse, mean costs (SD) }\end{array}$ & $€ 91.82 / € 33.30$ & $€ 2(€ 18)$ & $€ 3(€ 28)$ & $€ 21(€ 76)$ & $€ 1(€ 14)$ & $€ 1(€ 5)$ & $€ 2(€ 10)$ & $€ 0(€ 4)$ \\
\hline $\begin{array}{l}\text { Increased the number of blood glucose } \\
\text { checks per day, mean costs (SD) } \ddagger\end{array}$ & $€ 0.27$ & $€ 1(€ 2)$ & $€ 2(€ 2)$ & $€ 2(€ 2)$ & $€ 2(€ 2)$ & $€ 1(€ 3)$ & $€ 2(€ 5)$ & $€ 1(€ 2)$ \\
\hline $\begin{array}{l}\text { Total healthcare utilisation and informal care } \\
\text { costs, mean costs (SD) }\end{array}$ & & $€ 98$ (€325) & $€ 46(€ 248)$ & $€ 426(€ 696)$ & $€ 4(€ 16)$ & $€ 131(€ 363)$ & $€ 863(€ 512)$ & $€ 4(€ 12)$ \\
\hline
\end{tabular}

${ }^{*}$ Besides inpatient day(s) (€480.29) it is assumed this event required an ambulance (€618.53) and an intravenous infusion (or injection) with glucose (€6.63). †Besides an ambulance (€618.53; 75\%) or visit by a general practitioner ( $€ 50.45 ; 25 \%)$, it is assumed that this event required an intravenous infusion (or injection) with glucose (€6.63; 75\% and €6.12; $25 \%)$.

‡Patients could choose between 1, 2 or 3 + extra tests. If they reported $3+$ tests, costs of blood glucose checks were based on the costs of three tests. $\mathrm{NSH}$, non-severe hypoglycaemia; SH, severe hypoglycaemia; T1DM, type 1 diabetes; T2DM, type 2 diabetes.

hypoglycaemia in the 4 weeks after baseline. Mean total 4-week healthcare and informal care costs were €98 (SD, $€ 325)$. Mean costs were higher for patients with T2DM than for patients with T1DM; $€ 131$ (SD, €363) compared with $€ 46$ (SD, €248). Mean costs of patients with hypoglycaemia including at least one severe event were $€ 426$ (SD, €696) and $€ 863$ ( $\mathrm{SD}, € 512$ ) in $\mathrm{T} 1 \mathrm{DM}$ and $\mathrm{T} 2 \mathrm{DM}$, respectively, compared with $€ 4$ (SD, €16) and $€ 4$ (SD, €12) in T1DM and T2DM, for patients with non-severe events only.

\section{Productivity losses}

Productivity losses are presented in table 4. Of the patients with a full-time or part-time job, $4 \%$ reported sick leave (T1DM, $5 \%$; T2DM, $2 \%$ ) with a mean of 6 days (SD, 8). Additionally, 8\% (T1DM, 12\%; T2DM, 2\%) and 6\% (T1DM, 9\%; T2DM, 0\%) of the patients with a full-time or part-time job arrived at work late or left work early for $\geq 1$ days, respectively.

\section{Per patient total 4-week costs}

Table 5 shows the per patient total 4-week costs of patients who experienced hypoglycaemia. Mean total 4-week costs were $€ 145$ (SD, $€ 613$ ). Mean costs were $€ 163$ (SD, $€ 870$ ) for patients with T1DM and $€ 134$ (SD, €364) for patients with T2DM. While productivity costs were the most important cost driver of hypoglycaemia in patients with T1DM (accounting for $72 \%$ of the total costs), costs of hypoglycaemia in patients with T2DM were almost entirely driven by costs within the healthcare sector (accounting for $98 \%$ of the total costs).

Mean costs of patients with hypoglycaemia including at least one severe event were $€ 1401$ (SD, €2,497) and €863 (SD, €512) in T1DM and T2DM, respectively, compared with €26 (SD, €81) and €7 (SD, €41) in T1DM and T2DM for patients with non-severe events only. The mean total costs of patients with T1DM experiencing at least one severe event were largely driven by two patients, one with sick leave from work for 21 days and one with sick leave from work for 10 days.

\section{Sensitivity analyses}

Results of the sensitivity analyses suggest that the impact of the assumptions on the mean total 4-week costs of patients experiencing hypoglycaemia was limited. If the proportion of patients treated at home by ambulance personnel was decreased to $50 \%$, total 4-week costs would decrease from $€ 145$ (SD, €613) to $€ 143$ (SD, $€ 609$ ). If the proportion of patients treated at home by ambulance personnel was increased to $100 \%$, total 4-week costs would increase to $€ 148$ (SD, $€ 617$ ). If the duration of assistance by an informal caregiver was doubled to 2 hours for T1DM and to 6 hours for T2DM, total 4-week costs would increase to $€ 149$ (SD, €616). If the hours that patients were absent from work were halved to 2 hours, total 4-week costs would decrease to $€ 137$ (SD, $€ 600)$. Lastly, if ambulance costs were 
Table 4 Productivity losses of patients experiencing hypoglycaemia in 4 weeks after baseline

\begin{tabular}{|c|c|c|c|c|c|c|c|}
\hline & \multirow{2}{*}{$\begin{array}{l}\begin{array}{l}\text { All } \\
(n=332)\end{array} \\
\begin{array}{l}\text { All } \\
(n=332)\end{array}\end{array}$} & \multicolumn{3}{|c|}{ T1DM $(n=130)$} & \multicolumn{3}{|c|}{ T2DM (n=202) } \\
\hline & & $\begin{array}{l}\text { All } \\
(n=130)\end{array}$ & $\begin{array}{l}\text { Patients } \\
\text { with } \\
\text { SH (n=13) }\end{array}$ & $\begin{array}{l}\text { Patients with } \\
\text { NSH }(n=117)\end{array}$ & $\begin{array}{l}\text { All } \\
(n=202)\end{array}$ & $\begin{array}{l}\text { Patients } \\
\text { with } \\
\text { SH }(n=30)\end{array}$ & $\begin{array}{l}\text { Patients with } \\
\text { NSH }(n=172)\end{array}$ \\
\hline \multicolumn{8}{|l|}{ Employment status - $n(\%)$} \\
\hline Full-time employment & $80(24)$ & $48(37)$ & $5(38)$ & $43(37)$ & $32(16)$ & $3(10)$ & $29(17)$ \\
\hline Part-time employment & $65(20)$ & $46(35)$ & $6(46)$ & $40(34)$ & $19(9)$ & $2(7)$ & $17(10)$ \\
\hline Student & $7(2)$ & $7(5)$ & $0(0)$ & $7(6)$ & $0(0)$ & $0(0)$ & $0(0)$ \\
\hline Pensioned & $142(43)$ & $14(11)$ & $0(0)$ & $14(12)$ & $128(63)$ & $19(63)$ & $109(63)$ \\
\hline Unemployed & $11(3)$ & $7(5)$ & $2(15)$ & $5(4)$ & $4(2)$ & $1(3)$ & $3(2)$ \\
\hline Other & $23(7)$ & $6(5)$ & $0(0)$ & $6(5)$ & $17(8)$ & $5(17)$ & $12(7)$ \\
\hline Missing & $4(1)$ & $2(2)$ & $0(0)$ & $2(2)$ & $2(1 \%)$ & $0(0)$ & $2(1)$ \\
\hline \multicolumn{8}{|c|}{ Within patients being full-time or part-time employed } \\
\hline & $\mathrm{n}=145$ & $\mathrm{n}=94$ & $n=11$ & $n=83$ & $n=51$ & $n=5$ & $n=46$ \\
\hline Sick leave from work, $\mathrm{n}(\%)$ & $6(4)$ & $5(5)$ & $5(45)$ & $0(0)$ & $1(2)$ & $0(0)$ & $1(2)$ \\
\hline Number of days, mean (SD) & $6.0(8.1)$ & $7.0(8.7)$ & $7.0(8.7)$ & - & $1.0(0.0)$ & - & $1.0(0.0)$ \\
\hline Arrived at work late, $\mathrm{n}(\%)$ & $12(8)$ & $11(12)$ & $3(27)$ & $8(10)$ & $1(2)$ & $0(0)$ & $1(2)$ \\
\hline Number of days, mean (SD) & $2.0(1.5)$ & $2.0(1.5)$ & $4.0(1.7)$ & $1.3(0.5)$ & $2.0(0.0)$ & - & $2.0(0.0)$ \\
\hline Left work early, n (\%) & $8(6)$ & $8(9)$ & $3(27)$ & $5(6)$ & $0(0)$ & $0(0)$ & $0(0)$ \\
\hline Number of days, mean (SD) & $1.9(1.5)$ & $1.9(1.5)$ & $2.0(1.0)$ & $1.8(1.8)$ & - & - & - \\
\hline
\end{tabular}

$\mathrm{NSH}$, non-severe hypoglycaemia; SH, severe hypoglycaemia; T1DM, type 1 diabetes; T2DM, type 2 diabetes.

increased with $20 \%$, total 4-week costs would increase to $€ 156$ (SD, €637).

The impact of the assumptions on the mean total 4-week costs of patients with hypoglycaemia including at least one severe event and on the costs of patients with non-severe events only was also limited.

\section{Cost per hypoglycaemic event}

Mean costs per hypoglycaemic event are presented in table 5 and amounted to $€ 19$ for patients with T1DM and $€ 47$ for patients with T2DM ( $€ 16$ and $€ 46$ if the number of events as registered in the patient diary was used (note that the number of events according to the patient diary were consistently higher than in the SAQ)). Mean costs of a severe event were $€ 828$ and $€ 508$ in T1DM and T2DM, respectively ( $€ 552$ and $€ 1036$ if the number of events as registered in the patient diary was used), whereas the costs of a non-severe event were almost zero.

\section{Total cost of hypoglycaemia in the Netherlands}

Given that $92 \%$ of the T1DM population experience at least one hypoglycaemic event in a 4-week period, and that the mean total 4-week costs are $€ 163$ (95\% CI $€ 12$ to $€ 314)$, total 4-week costs in the entire Dutch T1DM population were estimated to amount to $€ 14.8$ million. Total 4-week costs in the entire Dutch T2DM population were estimated to amount to $€ 12.2$ million given that $43 \%$ of the insulin-treated T2DM population experience at least one hypoglycaemic event and that the mean total 4-week costs are $€ 134$ (95\% CI $€ 83$ to $€ 184$ ). Total yearly costs of hypoglycaemia were estimated to be $€ 352.3$ million for the entire patient T1DM and T2DM population in the Netherlands (healthcare costs, €201.4 million; informal care costs, €8.3 million; productivity costs, €142.6 million). Using the boundaries of the $95 \%$ CI of the per patient total 4-week costs, total yearly costs of hypoglycaemia in the Netherlands were estimated to range from $€ 112.5$ to $€ 590.8$ million.

\section{Per patient total costs based on part 1 of the SAQ}

Mean total 6-month costs of patients experiencing hypoglycaemia including at least one severe event were $€ 1132$ (SD, 2933) for patients with T1DM and $€ 586$ (SD, 1439) for patients with T2DM using part 1 of the questionnaire, corresponding to $€ 189$ and $€ 98$ per month. The costs within the healthcare sector are the most important cost driver of hypoglycaemia in both patients with T1DM and T2DM (see the online supplementary tables 1-4).

\section{DISCUSSION}

This is the first study providing information on the costs of hypoglycaemia among insulin-treated patients with T1DM and T2DM in the Netherlands. The study shows that the economic burden is substantial. Mean 4-week costs of patients who experienced hypoglycaemia were $€ 145$ (SD, €613). In the Netherlands in 2011, the costs of diabetes care amounted to 1.7 billion Euros. ${ }^{17}$ Healthcare costs of hypoglycaemia in the Netherlands were estimated 
Table 5 Per patient total 4-week costs of patients experiencing hypoglycaemia and costs per event

\begin{tabular}{|c|c|c|c|c|c|c|c|}
\hline & \multirow{2}{*}{$\begin{array}{l}\text { All }(n=332) \\
\begin{array}{l}\text { All } \\
(n=332)\end{array}\end{array}$} & \multicolumn{3}{|c|}{ T1DM $(n=130)$} & \multicolumn{3}{|c|}{ T2DM (n=202) } \\
\hline & & All $(n=130)$ & $\begin{array}{l}\text { Patients with } \\
\text { SH }(n=13)\end{array}$ & $\begin{array}{l}\text { Patients } \\
\text { with NSH } \\
(\mathrm{n}=117)\end{array}$ & All $(n=202)$ & $\begin{array}{l}\text { Patients with } \\
\text { SH }(n=30)\end{array}$ & $\begin{array}{l}\text { Patients } \\
\text { with NSH } \\
(\mathrm{n}=172)\end{array}$ \\
\hline \multicolumn{8}{|l|}{ Per patient total 4-week costs } \\
\hline $\begin{array}{l}\text { Costs within the healthcare sector } \\
\text { (including informal care), mean costs } \\
\text { (SD) (min-max) }\end{array}$ & $\begin{array}{l}€ 98(€ 325) \\
(€ 0-€ 2101)\end{array}$ & $\begin{array}{l}€ 46(€ 248) \\
(€ 0-€ 2101)\end{array}$ & $\begin{array}{l}€ 426(€ 696) \\
(€ 14-€ 2101)\end{array}$ & $\begin{array}{l}€ 4(€ 16) \\
(€ 0-€ 153)\end{array}$ & $\begin{array}{l}€ 131(€ 363) \\
(€ 0-€ 1654)\end{array}$ & $\begin{array}{l}€ 863(€ 512) \\
(€ 42-€ 1654)\end{array}$ & $\begin{array}{l}€ 4(€ 12) \\
(€ 0-€ 78)\end{array}$ \\
\hline $\begin{array}{l}\text { Per patient total 4-week costs of } \\
\text { patients experiencing hypoglycaemia, } \\
\text { mean costs (SD) (min-max) }\end{array}$ & $\begin{array}{l}€ 145(€ 613) \\
(€ 0-€ 8678)\end{array}$ & $\begin{array}{l}€ 163(€ 870) \\
(€ 0-€ 8678)\end{array}$ & $\begin{array}{l}€ 1401(€ 2497) \\
(€ 14-€ 8678)\end{array}$ & $\begin{array}{l}€ 26(€ 81) \\
(€ 0-€ 638)\end{array}$ & $\begin{array}{l}€ 134(€ 364) \\
(€ 0-€ 1654)\end{array}$ & $\begin{array}{l}€ 863(€ 512) \\
(€ 42-€ 1654)\end{array}$ & $\begin{array}{l}€ 7(€ 41) \\
(€ 0-€ 525)\end{array}$ \\
\hline \multicolumn{8}{|l|}{ Costs per event } \\
\hline Total costs per event (based on SAQ) & $€ 28$ & $€ 19$ & $€ 828$ & $€ 3$ & $€ 47$ & $€ 508$ & $€ 3$ \\
\hline $\begin{array}{l}\text { Number of events based on patient } \\
\text { diary§ }\end{array}$ & 1923 & 1339 & 33 & 1139 & 584 & 25 & 483 \\
\hline $\begin{array}{l}\text { Total costs per event (based on } \\
\text { patient diary) } \|\end{array}$ & $€ 25$ & $€ 16$ & $€ 552$ & $€ 3$ & $€ 46$ & $€ 1036$ & $€ 2$ \\
\hline
\end{tabular}

*The number of events excludes nocturnal events in order to prevent double counting. The number of events in patients with at least one severe event excludes non-severe events.

†Two patients experienced three events requiring assistance from another person to administer carbohydrate and/or glucagon, and two patients had two of these events, which increases the total number of events in the population.

$\ddagger$ Six patients experienced more than one event requiring assistance from another person to administer carbohydrate and/or glucagon, with one patients having six of these events.

$\S N u m b e r$ of events in patients with $\mathrm{SH}$ and NSH are limited to the number of severe and non-severe events, respectively, as reported within these groups.

IPlease note that the SD could not be calculated because costs per event were calculated by dividing total population costs by the total number of events in the population, but is expected to be substantial.

$\mathrm{NSH}$, non-severe hypoglycaemia; SH, severe hypoglycaemia; T1DM, type 1 diabetes; T2DM, type 2 diabetes.

to be $€ 201.4$ million per year, corresponding to $12 \%$ of the total healthcare costs of diabetes in the Netherlands. The total yearly costs of hypoglycaemia in the Netherlands, including informal care costs and productivity costs, were estimated to be $€ 352.3$ million.

The healthcare costs of hypoglycaemia in the Netherlands might seem relatively high with respect to the total costs of diabetes, but the total costs of diabetes might miss important diabetes-related costs, such as the costs of complications (eg, heart attack, stroke, eye problems and kidney disease). Total yearly costs of hypoglycaemia have been estimated in different countries, ${ }^{6-10}$ and all of these estimates are considerably lower than the costs we estimated. A comparison of healthcare costs between countries is complicated by practice variation, differences in the incentives to physicians and institutions and differences in relative and absolute prices. ${ }^{18}$ These differences should be taking into account when making international comparisons of healthcare costs. Nevertheless, possible explanations for the observed differences might be: first, one Swedish study was limited to the total yearly costs of T2DM, ${ }^{6}$ whereas we estimated total yearly costs of both T1DM and T2DM. Furthermore, this study only assessed costs of hypoglycaemic events that were classified as severe events in our study. Second, some studies were limited to healthcare costs, ${ }^{89}$ while we also took into account informal care costs and productivity costs. Third, different assumptions were made regarding the incidence of hypoglycaemia: while one study assumed an event rate of 0.09 per patient with T2DM per year (ie, 0.24 in insulin users and 0.04 in patients using oral antidiabetic agents) ${ }^{6}$ the incidence among insulin-treated patients with T2DM in our study varied from 571 to 584 events in the 4-week follow-up period (ie, 15.8-16.2 per patient per year). Fourth, the number of patients in other countries was considerably lower than in the Netherlands.

Interestingly, the costs per hypoglycaemic event as calculated in our study were considerably lower than the costs as estimated in other studies. ${ }^{67}$ Again it should be noted that comparing healthcare costs between countries is complicated. Nevertheless, one of the explanations for the difference is the definition of a severe event which was limited to events resulting in hospitalisation in one study. ${ }^{6}$ An Italian study presented resource utilisation and productivity losses per person-years, which complicates comparisons of their estimates of cost per episode 
to the estimates in the current study. ${ }^{10}$ The cost estimates in that study seem to be higher because of a longer stay in hospital and larger productivity losses for patients and caregivers. In contrast to the Italian study, work days lost by family members are not taken into account in our study, to avoid possible double counting with informal care time. A Danish study found lower costs per hypoglycaemic event than the costs we calculated, but in this study, costs were limited to healthcare costs. ${ }^{9}$

Some limitations to the data and methods deserve mentioning. First, there is large variation in the per patient costs. This can be explained by the skewed distribution of the data, that is, a small number of patients has very high costs (eg, while the mean total 4-week costs are $€ 145$ (SD, 613), 25 out of 332 patients (8\%) have costs $>€ 1000)$. This is frequently observed in costing studies. Further research, preferably with larger sample sizes, should confirm the results of our study.

Second, there is a large discrepancy between the per patient costs of patients experiencing hypoglycaemia including at least one severe event between part 1 and part 2 of the SAQ. The monthly costs based on part 1 of the questionnaire are much lower than the costs based on part 2 (ie, $€ 188$ and $€ 100$ vs $€ 1401$ and $€ 863$ in T1DM and T2DM, respectively). There might be several explanations: first, the results from part 1 might suffer from recall bias, since patients were asked about healthcare use in the previous 6 months and productivity losses in the previous year and as a consequence they might not remember using healthcare or being absent from work. As a result, the costs based on part 1 of the SAQ might be underestimated. Second, the results from part 2, especially those related to T1DM, are largely driven by two patients (ie, one with sick leave from work for 21 days and one with sick leave from work for 10 days).

Third, not all patients $(88 \%)$ who participated in the study and completed part 1 of the SAQ filled in part 2 of the SAQ and the diary. A comparison of the baseline characteristics (ie, age, gender, years with diabetes and years on insulin) of the patients who did and did not complete part 2 did not show significant differences, suggesting that the patients completing part 2 are representative of all patients participating in the HAT study (although non-significant findings might be related to small sample size). The only significant difference we found was a difference in age, that is, the patients who did not complete part 2 were younger than the patients who did complete part 2. This is explained partly by the type of diabetes among the two groups, that is, $15 \%$ of the patients with T1DM did not complete part 2 compared with $8 \%$ of the patients with T2DM. However, since all results are reported separately for patients with T1DM and T2DM, the impact of the potential under-representation of patients with T1DM is limited. It is further assumed that the samples (T1DM and T2DM) reflect the total insulin-treated T1DM and T2DM population (treated with insulin for at least 12 months) in the Netherlands, because all consecutive patients fulfilling the inclusion criteria were enrolled during routine scheduled clinical appointments with their healthcare provider. Demographic properties (age and gender) were similar in our study compared with the overall diabetes population in the Netherlands. ${ }^{19}$ Studies in other Western European countries show similar results with respect to the incidence and prevalence of hypoglycaemic events. ${ }^{420}$ The HAT study only included patients using insulin for at least 12 months. As patients who started using insulin more recently receive extra training about the risks of hypoglycaemia, they might be more focused on hypoglycaemic events and might be more in control when these occur. Consequently, the number of hypoglycaemic events might be lower compared with patients who are treated with insulin for $>12$ months. Since the number of newly treated patients $(<12$ months insulin use) is likely to be low, the impact on the results would be limited. ${ }^{4}$ Nonetheless, these patients were excluded from the analyses, so that the sample consisted of patients in which changes in insulin treatment were not expected.

Fourth, the incidence of hypoglycaemic events according to the patient diary was higher than reported in the SAQ. As mentioned by Khunti et at $t^{t}$, results from the SAQ might suffer from recall bias and the number of events might therefore be underestimated. ${ }^{4}$ On the contrary, double counting might occur in the SAQ in case a patient had an event resulting in hospital admission or an event requiring assistance from medical personnel but not requiring hospital admission and required assistance from another person for the same event. As a consequence, results from the SAQ might be overestimated. Although we present the costs per event based on both incidences, we believe that the cost per event based on the incidence as estimated from the SAQ is more reliable, as data on healthcare utilisation and frequency of hypoglycaemic events were derived from the same source. Nevertheless, the number of severe events seems relatively high, that is, 22 events in 13 patients with T1DM and 51 events in 30 patients with T2DM in a 4-week period. Two patients with T1DM experienced three events requiring assistance from another person to administer carbohydrate and/or glucagon and two patients had two of these events, which increases the total number of events in the population. Similarly, there were six patients with T2DM with more than one event requiring assistance from another person to administer carbohydrate and/or glucagon with one patients having six of these events.

Fifth, productivity losses due to a reduced ability to work efficiently (ie, presenteeism) were not taken into account, because no data about presenteeism were available. Since it seems plausible that patients who experienced a hypoglycaemic event but are not absent from work will work less efficiently, total productivity costs may be underestimated. Additionally productivity costs may be underestimated, because productivity losses of unpaid work were neglected (eg, household activities). In contrast, productivity losses could be overestimated because patients might have attributed productivity losses to hypoglycaemia that were actually related to other 
causes (eg, comorbidities). However, as the questionnaire specifically asks for productivity losses that were related to hypoglycaemia, such a potential overestimation is likely to be limited. Future studies could use a control group consisting of patients with diabetes but without hypoglycaemia to address this issue.

In conclusion, this study showed that the economic burden of hypoglycaemia is substantial, especially the burden of severe events. Important differences between the costs of hypoglycaemia in T1DM and T2DM were found. While productivity costs are the most important cost driver of hypoglycaemia in patients with T1DM, costs within the healthcare sector are the most important cost driver of hypoglycaemia in patients with T2DM. As the costs of hypoglycaemia are substantial, the prevention of hypoglycaemia could not only reduce the burden for patients, but also the economic burden to society, if the costs of prevention are smaller than the costs of hypoglycaemia. Increasing awareness among physicians about the frequent occurrence of hypoglycaemia is essential to prevent hypoglycaemia; as patients might not always report these for various reasons, including fear or shame, or because they do not see the relevance, physicians might be unaware of (the frequency of) hypoglycaemic events. Furthermore, it is important to incorporate the costs of hypoglycaemia in cost-effectiveness analysis of treatments for diabetes, for example, to study potential cost-savings if treatment reduces the number of (severe) hypoglycaemic events. However, given the large variation in costs per event, the results from this study should be used carefully and tested using sensitivity analyses to acknowledge the uncertainty around our estimates.

Acknowledgements The authors acknowledge Eline Huisman and Marleen Schoonen (both employed by Novo Nordisk during the conduct of the study) for their support in the interpretation of the results.

Contributors Catherine F. Enters-Weijnen and Petronella H. Geelhoed-Duijvestijn: recruited patients for the HAT study and were part of the HAT Investigator Group. Saskia de Groot: analysed the data from the HAT study (ie, data from Dutch patients only). All authors: interpretation of the results and the writing of the manuscript.

Funding This study was financially supported by Novo Nordisk BV.

Competing interests Saskia de Groot reports grants from Novo Nordisk, during the conduct of the study. Petronella H. Geelhoed-Duijvestijn reports grants and personal fees from Novo Nordisk, personal fees from Metronic, personal fees from Abbott, outside the submitted work. Tim A. Kanters reports grants from Novo Nordisk, during the conduct of the study. Catherine F. Enters-Weijnen has nothing to disclose.

Patient consent Obtained.

Ethics approval The Global HAT study was conducted in accordance with the Declaration of Helsinki; Ethical Principles for Medical Research Involving Human Patients. The protocol was subject to review/approval by appropriate countryspecific regulatory agencies/ethics committees.

Provenance and peer review Not commissioned; externally peer reviewed.

Data sharing statement The data generated during and/or analysed during the current trial are available from the corresponding author on reasonable request.
Open Access This is an Open Access article distributed in accordance with the Creative Commons Attribution Non Commercial (CC BY-NC 4.0) license, which permits others to distribute, remix, adapt, build upon this work non-commercially, and license their derivative works on different terms, provided the original work is properly cited and the use is non-commercial. See: http://creativecommons.org/ licenses/by-nc/4.0/

(c) Article author(s) (or their employer(s) unless otherwise stated in the text of the article) 2018. All rights reserved. No commercial use is permitted unless otherwise expressly granted.

\section{REFERENCES}

1. International Diabetes Federation. IDF diabetes atlas, 2013.

2. Volksgezondheidenzorg.info. Diabetes mellitus. https://www. volksgezondheidenzorg.info/onderwerp/diabetes-mellitus (accessed 24 Jul 2017).

3. Baan CA, Schoemaker CG, Jacobs-van der Bruggen MAM, et al. Diabetes tot 2025, preventie en zorg in samenhang. Bilthoven: Rijksinstituut voor Volksgezondheid en Milieu, 2009.

4. Khunti K, Alsifri S, Aronson R, et al. Rates and predictors of hypoglycaemia in 27585 people from 24 countries with insulintreated type 1 and type 2 diabetes: the global HAT study. Diabetes Obes Metab 2016;18:907-15.

5. Donnelly LA, Morris AD, Frier BM, et al. Frequency and predictors of hypoglycaemia in Type 1 and insulin-treated Type 2 diabetes: a population-based study. Diabet Med 2005;22:749-55.

6. Jönsson L, Bolinder B, Lundkvist J. Cost of hypoglycemia in patients with Type 2 diabetes in Sweden. Value Health 2006 9:193-8.

7. Parekh WA, Ashley D, Chubb B, et al. Approach to assessing the economic impact of insulin-related hypoglycaemia using the novel local impact of hypoglycaemia tool. Diabet Med 2015;32:1156-66.

8. Lyngsie PJ, Lopes S, Olsen J. Incidence and cost of hypoglycemic events requiring medical assistance in a hospital setting in Denmark. J Comp Eff Res 2016;5:239-47.

9. Hoskins N, Tikkanen CK, Pedersen-Bjergaard U. The economic impact of insulin-related hypoglycemia in Denmark: an analysis using the local impact of hypoglycemia tool. J Med Econ 2017;20:363-70.

10. Giorda CB, Rossi MC, Ozzello O, et al. Healthcare resource use, direct and indirect costs of hypoglycemia in type 1 and type 2 diabetes, and nationwide projections. Results of the HYPOS-1 study. Nutr Metab Cardiovasc Dis 2017;27:209-16.

11. Workgroup on Hypoglycemia, American Diabetes Association. Defining and reporting hypoglycemia in diabetes: a report from the American diabetes association workgroup on hypoglycemia. Diabetes Care 2005;28:1245-9.

12. Kanters TA, Bouwmans CAM, van der Linden N, et al. Update of the dutch manual for costing studies in health care. PLoS One 2017;12:e0187477.

13. Zorginstituut Nederland. Reimbursement and quality of blood glucose test material, an analysis of developments [in Dutch: bloedglucosetestmateriaal: vergoeding \& kwaliteit, analyse van ontwikkelingen 2009-2015], 2016.

14. Zorginstituut Nederland. Drug costs [in Dutch: Medicijnkosten]. 2017 http://medicijnkosten.nl/.

15. Stichting Farmaceutische Kengetallen. Long-acting insulins grow strongly [in Dutch: langwerkende insulines maken sterke groei door]. Pharmaceutisch weekblad, 2015:150.

16. Centraal Bureau voor de Statistiek. Consumer price index [in Dutch: jaarmutatie consumentenprijsindex; vanaf 1963], 2017.

17. Rijksinstituut voor Volksgezondheid en Milieu (RIVM). RIVM cost of illness database [in Dutch: RIVM kosten van ziekten database], 2013.

18. Drummond MF, Sculpher MJ, Claxton K, et al. Methods for the economic evaluation of health care programmes. 4th ed. Oxford: Oxford University Press, 2015.

19. Ursum J, Hek K, Spronk I, et al. How often does diabetes occur and in whom? From: NIVEL Care Registrations first line [in Dutch: Hoe vaak komt diabetes voor en bij wie? Uit: NIVEL Zorgregistraties eerste lijn]. 2016 www.nivel.nl/node/4315 (accessed 5 Dec 2017).

20. Khunti K, Alsifri S, Aronson R, et al. Impact of hypoglycaemia on patient-reported outcomes from a global, 24-country study of 27,585 people with type 1 and insulin-treated type 2 diabetes. Diabetes Res Clin Pract 2017;130:121-9. 